\title{
EFISIENSI PENGGUNAAN FAKTOR PRODUKSI PADA USAHA TANI JAMUR TIRAM (Pleurotus ostreatus Jacq.)
}

\section{THE EFFICIENCY OF PRODUCTION FACTOR USE IN OYSTER FARMING (Pleurotus ostreatus Jacq.)}

\author{
Dedi Sufyadi $^{1 *}$, Cancan Gunawan Apidianur² \\ ${ }^{1}$ Universitas Siliwangi, J1.Siliwangi 24 Kota Tasikmalaya \\ ${ }^{2}$ Dinas Pertanian Kabupaten Tasikmalaya, Jl. Singaparna \\ *E-mail: dedisufyadi@unsil.ac.id
}

(DIterima 29-12-2019; Disetujui 20-01-2020)

\begin{abstract}
ABSTRAK
Penelitian ini bertujuan untuk mengetahui faktor-faktor produksi yang berpengaruh terhadap usahatani jamur tiram dan menganalisis tingkat efisiensi penggunaan faktor produksi pada usahatani jamur tiram di UPT Pertanian Wilayah Sukaraja. Metode yang digunakan dalam penelitian ini adalah survey dengan pendekatan deskriptif eksploratif. Data yang digunakan adalah data primer, data sekunder yang diperoleh melalui wawancara, kuesioner dan studi pustaka. Hasil analisis menunjukkan total nilai koefisien sebesar 2,143. Nilai ini menunjukkan skala produksi petani jamur tiram berada pada tahap I atau increasing return to scale (IRS). Besarnya nilai koefisien determinasi $\left(\mathrm{R}^{2}\right)$ sebesar 92,3 persen artinya 92,3 persen produksi jamur tiram dapat dijelaskan oleh variabel penggunan faktor produksi, sedangkan sisanya 7,7 persen dipengaruhi oleh variabel lain selain penggunaan faktor produksi yang tidak dimasukkan ke dalam model. Penggunaan faktor produksi yang berpengaruh signifikan terhadap variasi produksi jamur tiram adalah lahan dan bekatul. Sementara bibit, serbuk gergaji, tenaga kerja, polybag, kapur, cincin paralon, karet dan kertas tidak berpengaruh signifikan.
\end{abstract}

Kata kunci: Efisiensi, faktor produksi, usahatani jamur tiram

\section{ABSTRACT}

This study aims to determine the factors of production that affect oyster mushroom farming and analyze the level of efficiency of the use of production factors on oyster mushroom farming in UPT Agriculture Area Sukaraja. The method used in this research is survey with explorative descriptive approach. The data used are primary data secondary data obtained through interviews, questionnaires and literature study. The results analsis show a total coefficient value of 2.143. This value indicates the scale of oyster mushroom production is in phase I or increasing return to scale (IRS). The value of the coefficient of determination $\left(R^{2}\right)$ is 92.3 percent means that 92.3 percent of oyster mushroom production can be explained by variable use of production factors, while the remaining 7.7 percent is influenced by other variables besides the use of production factors not included in the model. The use of production factors that significantly influence the variation of oyster mushroom production are land and sawdust. While seeds, bran labor polybag, lime, paralon ring, rubbe and paper have no significant effect.

Keywords: Efficiency, production factor, oyster mushroom farming

\section{PENDAHULUAN}

Jamur merupakan salah satu jenis produk hortikultura yang dapat dikembangkan dan diarahkan untuk dapat memperbaiki keadaan gizi masyarakat. Budidaya jamur konsumsi di Indonesia menunjukkan perkembangan yang menggembirakan. Saat ini, Indonesia 
sudah termasuk salah satu negara pemasok utama jamur dunia, akibatnya kebutuhan dalam negeri justru terabaikan (BPS, 2014).

Permintaan pasar jamur dunia masih sangat terbuka lebar, terbukti setiap bulannya permintaan komoditas ekspor jamur cenderung mengalami peningkatan yang cukup signifikan. Saat ini beberapa negara yang menjadi konsumen jamur terbesar di dunia antara lain: Amerika Serikat, Kanada, Jerman, Jepang, Hongkong, Belgia, Inggris, Belanda, dan 1talia. Rata-rata tingkat konsumsi jamur penduduk Kanada dan negara-negara Eropa melebihi $1,5 \mathrm{~kg} / \mathrm{kapita} / \mathrm{tahun}$.

Disamping permintaan pasar ekspor-impor tersebut, pasar domestik juga mengalami peningkatan yang cukup pesat setiap harinya. Sekarang ini produk jamur tidak hanya dipasarkan dalam keadaan segar saja, namun juga mulai diolah menjadi aneka macam produk olahan jamur. Sehingga tidak menutup kemungkinan bila para pelaku bisnis restoran, katering, ataupunhotelhoteldiberbagaidaerahmulaimembutuhkan jamur untuk memanjakan konsumen mereka. Peluang ini semakin memperluas jangkauan pasar jamur, dan memberikan banyak keuntungan bagi masyarakat yang telah menekuni bisnis budidaya jamur.
Sampai saat ini produsen jamur paling besar terdapat di Pulau Jawa. Berdasarkan data statistik pada tahun 2014 setiap hari Jawa Barat memproduksi 15-20 ton jamur merang dan 10 ton jamur tiram. Sementara Jawa Tengah sebagai sentra jamur kuping dan shiitake, setiap harinya memproduksi 1 ton jamur kuping dan $500 \mathrm{~kg}$ jamur shiitake. Bahkan di Kota Blitar, Jawa Timurmulai mengekspor seperempat kontainer jamur tiram putih ke negara Taiwan. Sebagian besar produksi jamur dipasarkan dalam bentuk segar. Jamur-jamur tersebut kebanyakan dipasarkan ke kota-kota besar yang menjadi tujuan pasar utama jamur selama ini (Ditjen Bina Produksi Hortikultura, 2015).

Produksi jamur tiram banyak dilakukan di daerah Jawa Barat, yang tercatat kurang lebih sekitar 10 ton produksi jamur tiram setiap hari. Beberapa daerah penghasil jamur tiram antara lain Karawang, Bogor, Bandung, dan Sukabumi, dalam bentuk segar maupun olahan. Selain daerah tadi, Kabupaten Tasikmalaya menjadi dareah yang mempunyai potensi untuk mengembangkan jamur tiram. Berikut ini data luas panen di Jawa Barat selama lima tahun. 
Jenis jamur yang biasa dibudidayakan petani adalah jenis jamur tiram, jamur merang dan amur shitake. Di Kabupaten Tasikmalaya pengembangan komoditas jamur tiram dimulai sejak tahun 2000 (Dinas Pertanian Kabupaten Tasikmalaya, 2014). Setiap tahunnya jumlah produksi jamur tiram yang ditawarkan di pasar selalu mengalami perubahan. tergantung dari jumlah jamur yang diproduksi. Sedangkan jumlahproduksi jamur sangat ditentukan oleh luas panen dan produktivitas usaha tani jamur yang dikelola oleh petani jamur. Pada tahun 2015 luas tanam di Kabupateen Tasikmalaya mencapai $28.244 \mathrm{~m}^{2}$ dengan jumlah produksi sebesar 365.858 kilogram jamur.

Tahun 2015, produksi jamur tiram di Kabupaten Tasikmalaya masih didominasi oleh beberapa kecamatan yaitu Kecamatan Cibalong, dan Kecamatan Sukaraja dan Kecamatan Salopa.Kecamatan-kecamatan tersebut secara administratif berada di UPT Pertanian Wilayah Sukaraja.

Petani pembudidaya jamur sebagai pelaksana dituntut untuk mengorganisasi tanah (alam), tenaga kerja dan modal yang ditujukankepada produksi guna menghasilkan laba atau tidak. Usahatani jamur tiram dikatakan berhasil apabila usahatani tersebut dapat menghasilkan pendapatan untuk membayar semua biaya dan alat yang diperlukan, dengan kata lain keberhasilan suatu usahatani berkaitan erat dengan pendapatan dan biaya yang dikeluarkan. Dalam budidaya jamur tiram terdapat banyak faktor yangmempengaruhi keputusan petani dalam mengusahakan lahan yang dimilikinya. Faktor ekonomi meliputi penguasaan modal, harapan keuntungan yang lebih besar, umur tanaman, kestabilan hasil produksi, mudah tidaknya hasil tersebut dijual sewaktu-waktu. Faktor teknis di antaranya adalah kualitas dan luas lahan yang dimiliki, ketahanan komoditas terhadap hama dan penyakit, potensi produksi, tingkat adaptasi dan kesesuaian dengan iklim. Faktor sosial meliputi tradisi dan kebiasaan yang telah berlangsung lama, usahatani tetangga, ketersediaan tenaga kerja, kepentingan petani dan keluarganya, tingkat pendidikan dan sebagainya.

Penelitian ini bertujuan untuk menganalisis faktor-faktor produksi yang berpengaruh terhadap usahatani jamur tiram dan untuk mengetahui efisiensi penggunaan faktor produksi pada usahatani jamur tiram di UPT Pertanian Wilayah Sukaraja. 


\section{METODE PENELITIAN}

Penelitian ini dilaksanakan pada bulan Pebruari sampai dengan bulan Agustus 2017 pada petani jamur tiram yang berada di wilayah kerja UPT Pertanian Wilayah Sukaraja, yaitu Kecamatan Sukaraja, Parungponteng, Cibalong, Tanjungjaya, Jatiwaras dan Salopa.

Metode yang digunakan dalam penelitian ini adalah Survey. Jenis data yang digunakan adalah data text dan data image. Data yang dikumpulkan terdiri dari data primer dan data sekunder. Pengumpulan data dilakukan teknikobservasi, wawancara dan dokumentasi. Observasi biasa diartikan sebagai pengamatan dan percatatan secara sisitematik terhadap gejala yang tampak pada obyek penelitian. Pemilihan lokasi penelitian dilakukan secara sengaja dipilih (purposive) yaitu di UPT Pertanian Wilayah Sukaraja. Pengambilan sampel dilakukan dengan menggunakan metode sensus, yaitu dengan mengambil seluruh petani pembudidaya jamur tiram yang berada di enam (6) kecamatan sejumlah 50 orang petani.

Tahap awal dari pembentukan model adalah penentuan variabel penelitian. Ada dua macam variabel yaitu variabel bebas dan variabel terikat. Yang menjadi variabel bebas adalah produksi jamur yang dihasilkan (Y). Sedangkan pemilihan variabel bebas (Xi) dilakukan dengan pertimbangan bahwa variabelvariabel tersebut mempunyai pengaruh yang besar terhadap variasi produksi. Spesifikasi double-log (Cobb Douglas) yang digunakan pada penelitian ini adalah:

$$
\begin{aligned}
& \operatorname{LnY}=\beta_{0}+\beta_{1} \operatorname{LnX} 1+\beta_{2} \operatorname{LnX} 2+\beta_{3} \operatorname{LnX} 3+ \\
& \beta_{4} \operatorname{LnX} 4+\beta_{5} \operatorname{LnX} 5+\beta_{6} \operatorname{LnX} 6+\beta_{7} \operatorname{LnX7}+ \\
& \beta{ }_{8} \operatorname{LnX} 8+\beta 9 \operatorname{LnX} 9+\beta_{10} \operatorname{LnX10}+\beta_{11} \operatorname{LnX11}
\end{aligned}
$$

Dimana:

$\mathrm{Y}=$ jumlah produksi jamur tiram $(\mathrm{kg})$.

$\mathrm{X} 1$ = luas lahan/bangunan $(\mathrm{m} 2)$

$\mathrm{X} 3$ = jumlah serbuk gergaji $(\mathrm{kg})$

$\mathrm{X} 4$ = jumlah bekatul $(\mathrm{kg})$

$\mathrm{X} 5$ = jumlah polybag yang digunakan $(\mathrm{kg})$

X6 = jumlah kapur yang digunakan $(\mathrm{kg})$ $\mathrm{X} 7=$ jumlah paralon yang digunakan (lth)

$\mathrm{X} 8$ = jumlah karet yang digunakan $(\mathrm{kg})$ X9 = jumlah kertas yang digunakan (rim) $\mathrm{X} 10=$ jumlah gas yang digunakan (tabung)

$\beta_{0}-\beta_{10}=$ besaran yang akan diduga $b_{o}=$ intersep

$b_{1}, b_{2}, b_{3}, b_{4} \ldots b_{10}=$ Elastisitas faktor produksi

Untuk mengetahui adanya pengaruh linear, maka perlu dilanjutkan dengan 
analisi persamaan regresi linear berganda dengan melihat nilaikoefisien determinasi (R2), nilai statistik $\mathrm{F}$ dan uji $\mathrm{T}$ untuk menguji ketepatan model regresi.

1) Koefisien determinasi $\left(R^{2}\right)$

$$
\text { Koefisien determinasi }
$$
merupakan besaran yang digunakan untuk menunjukkan seberapa besar keseluruhan model dalam menerangkan nilai variabel terikat. Dalam penelitian ini, ingin diketahui seberapa besar persentase faktor-faktor produksi (X) dalam mempengaruhi hasil produksi (Y).

2) Uji F

Uji F dilakukan untuk mengetahui pengaruh variabel bebas (X) secara keseluruhan terhadap variabel terikat (Y). Jadi, digunakan untuk melihat apakah semua faktor produksi terhadap produksi jamur tiram.

Hipotesis nol yang diuji adalah:

$H_{0}: \beta_{1}, \beta_{2}, \beta_{3} \ldots \beta_{11}=0$

$\mathrm{H}_{\mathrm{a}}: \beta_{1}, \beta_{2}, \beta_{3} \ldots \beta_{11} \neq 0$ (paling sedikit ada

$1 \beta$ yang tidak sama dengan nol.

Hipotesis penelitian ini adalah:

$\mathrm{H}_{0}: \beta_{1}, \beta_{2}, \ldots \beta_{11}=0 \quad$ : Tidak terdapat pengaruh variabel bebas terhadap produksi jamur tiram.

Ha $: \beta_{1}, \beta_{2}, \ldots \beta_{11} \neq 0 \quad$ : Tidak terdapat pengaruh variabel bebas terhadap produksi jamur tiram.
Kriteria pengambilan keputusan uji adalah:

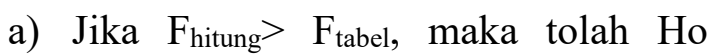
terima $\mathrm{Ha}$, artinya semua variabel bebas (X) berpengaruh nyata terhadap variabel terikat (Y)

b) Jika $F_{\text {hitung }}<F_{\text {tabel, }}$ maka terima Ho tolak Ha, artinya semua variabel bebas (X) tidak berpengaruh nyata terhadap variabel terikat(Y)

3) $\mathrm{Uji} T$

Uji t digunakan untuk mengetahui pengaruh secara parsial masing-masing variabel bebas (Xi) terhadap variabel terikat (Y). Jadi, setiap faktor-faktor produksi diuji t untukmengetahui apakah variabel tersebut berpengaruh terhadap produksi jamur tiram.

Hipotesis nol yang diuji adalah :

$$
\begin{aligned}
& \mathrm{H}_{\mathrm{o}}: \beta=0 \\
& \mathrm{Ha}: \beta \neq 0
\end{aligned}
$$

Hipotesis penelitian ini adalah :

$\mathrm{H}_{\mathrm{o}}: \beta=0$ : Tidak terdapat pengaruh variabel bebas $\left(\mathrm{x}_{\mathrm{i}}\right)$ terhadap produksi jamur tiram

Ha $: \beta \neq 0$ : Terdapat pengaruh variabel bebas $\left(\mathrm{x}_{\mathrm{i}}\right)$ terhadap produksi jamur tiram

4) Analisis efisiensi penggunaan faktor produksi

Elastisitas produksi menunjukan perbandingan presentase perubahan 
output dengan perubahan input yang digunakan. Sehingga terdapat tiga kemungkinan yaitu:

a) Jika $\beta_{1}+\beta_{2}+\ldots+b_{11}<1$ maka terjadi decreasing return to scale, hal ini berartipenambahan faktor produksi dalam proses produksi akan menyebabkan penurunan tambahan hasil.

b) Jika $\beta_{1}+\beta_{2}+\ldots+b_{11}>1$ maka terjadi increasing return to scale, hal ini berartipenambahan faktor produksi akan meningkatkan tambahan hasil produksi.

c) Jika $\beta_{1}+\beta_{2}+\ldots+b_{11}=1$ maka terjadi constant return to scale, hal ini berartipenambahan faktor produksi proporsional dengan penambahan hasil produksi.

Tingkat efisiensi dihitung berdasarkan penggunaan faktor produksi dihitung berdasarkan konsep ekonomi yaitu menggunakan perbandingan nilai produk marginal ke i $\left(\mathrm{NPM}_{\mathrm{xi}}\right)$ dengan harga faktor produksi ke $\mathrm{i}\left(\mathrm{P}_{\mathrm{xi}}\right)$.

Kriteria pengambilan keputusan uji adalah:

$\frac{N P M_{x 1}}{P x i}=1:$ Alokasi penggunaan faktor produksi ke-i pada budidaya jamur tiram secara ekonomi sudah efisien.

$\frac{N P M_{x 1}}{P x i}>1$ : Alokasi penggunaan produksi pada budidaya jamur tiram secara ekonomi belum efisien karena itu perlu ditingkatkan pemakaiannya.

$\frac{N P M_{x 1}}{P x i}<1$ : Alokasi penggunaan faktor produksi ke-i pada budidaya jamur tiram secara ekonomi tidak efisien karena itu perlu dikurangi pemakaiannya.

Selanjutnya penggunaan inputyangoptimal dalam proses produksi jamur tiram penting untuk diketahui. Secara matematis kriteria umum penggunaan input optimal tersebut dapat digambarkan sebagai berikut:

$\Pi=\mathrm{TR}-\mathrm{TC}$

$=P_{y} . Y-\sum v_{i} x_{i}-B$

$=P_{y} . f(x i)-\sum v_{i} x_{i}-B$

$\frac{N P M_{1}}{v_{1}}=\frac{N P M_{2}}{v_{2}}=\frac{N P M_{3}}{v_{3}}$

Maka, Penentuan penggunaan input optimal untuk setiap input adalah:

$\frac{N P M_{1}}{v_{1}}=1$, atau $\frac{N P M}{B K M}=1,=$ efisien

Jika, $\frac{N P M}{B K M}<1=$ tidak efisien dan harus mengurangi jumlah input.

Jika, $\frac{N P M}{B K M}>1=$ belum efisien dan harus menambah jumlah input. 
Keterangan:

NPM $=$ Nilai Produk Marginal

$\mathrm{BKM}=$ Biaya Korbanan Marginal $\left(\mathrm{v}_{\mathrm{i}}\right.$

\section{HASIL DAN PEMBAHASAN}

\section{Analisis model fungsi produksi}

Analisis ini dilakukan untuk mengetahui seberapa besar pengaruh dari masing-masing faktor produksi sebagai variabel independent terhadap hasil produksi jamur tiram sebagai variabel dependent. Selain itu analisis ini juga digunakan untuk mengetahui besarnya elastisitas dari masing-masing variabel independen terhadap varabel dependent. Selanjutnya berkenaan dengan fungsi produksi Cobb-Douglass dalam analisis ini maka data ditransformasikan kedalam bentuk logaritma natural $(\ln )$ agar dapat dianalisis regresi secara linier.

\section{Uji F dan Uji T}

Tabel 1. Analisis Varian

\begin{tabular}{|c|c|c|c|c|c|}
\hline \multicolumn{6}{|c|}{ ANOVA $^{b}$} \\
\hline Model & $\begin{array}{c}\text { Sum of } \\
\text { Squares }\end{array}$ & df & $\begin{array}{l}\text { Mean } \\
\text { Square }\end{array}$ & $\mathbf{F}$ & Sig. \\
\hline Regression & 2.994 & 11 & .272 & 41.446 & $.000^{\mathrm{a}}$ \\
\hline Residual & .250 & 38 & .007 & & \\
\hline Total & 3.244 & 49 & .272 & & \\
\hline
\end{tabular}

Hasil olah data untuk ANOVA menunjukkan nilai $\mathrm{F}$ (Value) $=41,446$ dengan nilai $\mathrm{P}(\mathrm{Prob}>\mathrm{F})$ atau signifikansi 0,000a memberikan informasi tentang signifikansi model pada taraf kepercayaan $95 \%(\alpha=0,05)$, ini berarti model yang dipakai signifikan secara statistik karena $\mathrm{P}$ $<\alpha=0,05(0,000<0,05)$. Karena model signifikan, maka penafsiran, peramalan atau inferensi yang lain dapat dilakukan dengan menggunakan model regresi tersebut. Nilai signifikansi dibawah atau sama dengan 0,05, maka Ha diterima dan Ho ditolak, artinya terdapat pengaruh signifikan antara penggunaan faktor produksi dengan produksi usahatani jamur tiram pada petani di UPT Pertanian Wilayah Sukaraja.

Penjumlahan koefisien dengan metode OLS adalah 10,143 menunjukkan nilai elastisitas produksi $>1$. Daerah tersebut berarti secara ekonomis penggunaan faktor produksi belum berada pada tingkat optimum sehingga tidak rasional apabila produsen tidak menambah input pada daerah ini. Nilai tersebut juga menunjukkan skala produksi petani jamur tiram berada pada tahap I atau increasing return to scale (IRS) karena koefisien bertanda positif dan nilainya lebih besar dari satu. Ini berarti, jika penggunaan masing-masing input produksi mengalami peningkatan sebesar satu persen, produksi jamur tiram akan meningkat lebih dari satu persen atau 10,143 persen. 
Selanjutnya untuk mengetahui pengaruh parsial dilakukan analisis uji $\mathrm{T}$. Nilai signifikansi dibawah atau sama dengan 0,05, maka Ha diterima dan Ho ditolak, artinya terdapat pengaruh antara penggunaan faktor produksi dengan produksi usahatani jamur tiram. Nilai koefisien b0 sebesar 5,126 berarti apabila variabel-variabel penggunaan faktor produksi sama dengan nol maka diperkirakan produksi jamur tiram akan meningkat.

Tabel 2. Nilai koefisien korelasi dan uji T

\begin{tabular}{|c|c|c|c|c|}
\hline \multirow[t]{2}{*}{ Model } & \multicolumn{2}{|c|}{$\begin{array}{l}\text { Unstandardized } \\
\text { Coefficients }\end{array}$} & \multirow[t]{2}{*}{$\mathrm{t}$} & \multirow[t]{2}{*}{ Sig. } \\
\hline & B & Std. Error & & \\
\hline L (Constant) & 5.126 & .379 & 13.520 & .000 \\
\hline $\operatorname{Lnx}_{1}$ & .891 & .117 & 7.610 & $.000^{*}$ \\
\hline $\operatorname{Lnx}_{2}$ & .076 & .062 & 1.224 & .229 \\
\hline $\operatorname{Lnx}_{3}$ & -.039 & .050 & -.772 & .445 \\
\hline $\operatorname{Lnx}_{4}$ & -.156 & .077 & -2.024 & $.050^{*}$ \\
\hline $\operatorname{Lnx}_{5}$ & 9.442 & .058 & 1.626 & 1.000 \\
\hline $\operatorname{Lnx}_{6}$ & .011 & .048 & .229 & .820 \\
\hline $\operatorname{Lnx}_{7}$ & .052 & .050 & 1.044 & .303 \\
\hline $\operatorname{Lnx}_{8}$ & -.008 & .010 & -.751 & .458 \\
\hline $\operatorname{Lnx}_{9}$ & -.042 & .043 & -.977 & .335 \\
\hline $\operatorname{Lnx}_{10}$ & -.017 & .064 & -.268 & .790 \\
\hline $\operatorname{Lnx}_{11}$ & -.067 & .065 & -1.029 & .310 \\
\hline
\end{tabular}

Berdasarkan hasil olah data tersebut, diperoleh persamaan regresi berikut:

$\mathrm{Y}=5,126+0,891 \operatorname{LnX} 1+0,076 \operatorname{Ln} \mathrm{X} 2$

0,039 LnX3 - 0,156 LnX4 + 9,442 LnX5

$+0,011 \operatorname{LnX} 6+0,052 \operatorname{LnX} 7-0,008 \operatorname{Ln}$

X8 - 0,042 LnX9 - 0,017 LnX10 LnX9 $0,067 \operatorname{LnX} 11$
Berdasarkan hasil uji $\mathrm{t}$ dengan metode OLS menunjukkan bahwa variabel penggunaan faktor produksi berpengaruh signifikan terhadap variasi produksi jamur tiram adalah lahan (X1) dan bekatul (X4). Sementara bibit (X2), serbuk gergaji (X3), tenaga kerja (X11). polybag (X5), kapur (X6) cincin paralon (X7). karet (X8), kertas (X9) dan gas (x10) tidak berpengaruh signifikan tetapi tetap diperhitungkan karena setiap peningkatan kedua faktor tersebut dapat meningkatkan produksi jamur tiram.

\section{Koefisien korelasi dan determinasi}

Tabel 3. Koefisien korelasi dan determinasi

$$
\begin{aligned}
& \text { Model } R \quad R \quad \text { Adjusted } \begin{array}{c}
\text { Std. Error Durbin- } \\
\text { of the }
\end{array} \\
& \text { 1 } 961^{\mathrm{a}} \quad 923 \text { Estimate Watson }
\end{aligned}
$$

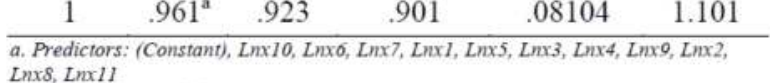

$$
\begin{aligned}
& \text { b. Dependent Variabel: Lny }
\end{aligned}
$$

Tabel di atas merupakan matrik inerkorelasi antara penggunaan faktor produksi dengan produksi jamur tiram. terdapat angka 0,923. Angka 0,961 merupakan $r$ hitung. Besarnya nilai korelasi ganda antara penggunaan faktor produksi terhadap produksi jamur tiram sebesar 0,923 . Besarnya nilai koefisien determinasi (R2) sebesar 92,3 persen artinya 92,3 persen produksi jamur tiram dapat dijelaskan oleh variabel penggunan faktor produksi, sedangkan sisanya 7,7 persen dipengaruhi oleh variabel lain 
selain penggunaan faktor produksi yang tidak dimasukkan ke dalam model.

\section{Efisiensi penggunaan faktor produksi}

\section{Efisiensi teknis}

Efisiensi teknis diambil dari nilai koefisien regresi atau elastisitas produksi dari masing-masing variabel faktor produksi. Secara umum tingkat efisiensi teknis petani jamur tiram di UPT Pertanian Wilayah Sukaraja dapat dikatakan belum efisien, hal ini ditunjukkan dengan nilai efisiensi teknis sebesar 10,143 (Ep>1). Hal ini mengindikasikan bahwa petani dapat menurunkan penggunaan input produksi jamur tiram sebesar 10,143 satuan untuk menghasilkan output yang sama ataupun dapat diartikan pada tingkat input dan teknologi yang sama.

Efisiensi teknis penggunaan faktor produksi pada usahatani jamur tiram pada UPT Pertanian Wilayah Sukaraja dapat dijelaskan sebagai berikut:

1). Penggunaan lahan pada usahatani jamur tiram pada UPT Pertanian Wilayah Sukaraja tidak efisien secara teknis $(0,891 \mathrm{Ep}<1)$

2). Penggunaan bibit pada usahatani jamur tiram pada UPT Pertanian Wilayah Sukaraja tidak efisien secara teknis $(0,076 \mathrm{Ep}<1)$
3). Penggunaan serbuk gergaji pada usahatani jamur tiram pada UPT Pertanian Wilayah Sukaraja tidak efisien secara teknis $(-0,039 \mathrm{Ep}<1)$.

4). Penggunaan bekatul pada usahatani jamur tiram pada UPT Pertanian Wilayah Sukaraja tidak efisien secara teknis $(-0,156 \mathrm{Ep}<1)$.

5). Penggunaan polybag pada usahatani jamur tiram pada UPT Pertanian Wilayah Sukaraja belum efisien secara teknis $(9,442 \mathrm{Ep}>1)$.

6). Penggunaan kapur pada usahatani jamur tiram pada UPT Pertanian Wilayah Sukaraja tidak efisien secara teknis $(0,011 \mathrm{Ep}<1)$.

7). Penggunaan cincin paralon pada usahatani jamur tiram pada UPT Pertanian Wilayah Sukaraja tidak efisien secara teknis $(0,052 \mathrm{Ep}<1)$.

8). Penggunaan karet dan kertas pada usahatani jamur tiram pada UPT Pertanian Wilayah Sukaraja tidak efisien secara teknis $(-0,008 \mathrm{Ep}<1)$

9). Penggunaan karet dan kertas pada usahatani jamur tiram pada UPT Pertanian Wilayah Sukaraja tidak efisien secara teknis $(-0,042 \mathrm{Ep}<1)$,

10). Penggunaan gas pada usahatani jamur tiram pada UPT Pertanian Wilayah Sukaraja tidak efisien secara teknis $(-0,017 \mathrm{Ep}<1)$, 
11). Penggunaan tenaga kerja pada usahatani jamur tiram pada UPT Pertanian Wilayah Sukaraja tidak efisien secara teknis $(-0,067 \mathrm{Ep}<1)$

\section{Efisiensi ekonomi}

Tabel 4. Efisiensi ekonomi

\begin{tabular}{lrrr}
\hline Variabel & \multicolumn{1}{c}{ NPM } & \multicolumn{1}{c}{ BKM } & Efisiensi Ekonomi \\
\hline Lahan & $443.995,044$ & $4.857,670$ & 91,401 \\
Bibit & $258.969,166$ & $50.000,000$ & 5,179 \\
Serbuk & $-33.960,980$ & 200,000 & $-169,805$ \\
Bekatul & $-851.337,356$ & $4.000,000$ & $-212,834$ \\
Polybag & 100.484 .812 & $20.000,000$ & $5,024,241$ \\
Kapur & $186.822,058$ & 750,000 & 249,096 \\
Cincin & $668.637,464$ & $20.000,000$ & 33,432 \\
Karet & $-917.435,595$ & $20.000,000$ & $-45,872$ \\
Kertas & $-882.582,081$ & $35.000,000$ & $-25,217$ \\
Gas & $-192.600,171$ & $22.000,000$ & $-8,755$ \\
T, Kerja & $-22.958,555$ & $35.000,000$ & $-0,656$ \\
\hline
\end{tabular}

Berdasarkan hasil penelitian diketahui bahwa tidak ada alokasi penggunaan sarana produksi pada usahatani jamur tiram pada UPT Pertanian Wilayah Sukaraja yang sudah mencapai tingkat efisisen secara ekonomi. Terdapat enam variabel yang mempunyai efisiensi ekonomi kurang dari satu dan semua bernilai negatif sehingga penggunaannya perlu dikurangi dan empat variabel mempunyai nilai positif dan lebih dari satu sehingga penggunaannya perlu ditingkatkan.

Untuk mengetahui berapa besar pengurangan dan penambahan alokasi penggunaan faktor produksi terkait dengan kondisi efisiensi ekonomi dapat dilihat dari kondisi optimal alokasi penggunaan faktor produksinya.

Tabel 5. Penggunaan inpit optimal

\begin{tabular}{lrrrr}
\hline Variabel & Aktual & NPM & $\begin{array}{r}\text { Kondisi } \\
\text { Optimal }\end{array}$ & \multicolumn{1}{c}{ Selisih } \\
\hline $\begin{array}{lrrrr}\text { Luas } \\
\text { lahan }\end{array}$ & 84,360 & 44.3995 .044 & 52,021 & $-32,339$ \\
Bibit & 12,337 & 258.969 .166 & 30,342 & 18,005 \\
Serbuk & 48,275 & -33.960 .98 & $-3,979$ & $-52,254$ \\
Bekatul & 7,703 & -8.513 .37 .356 & $-99,747$ & $-107,450$ \\
Polybag & 3,950 & 100.484 .812 & $11.773,264$ & $11.769,314$ \\
Kapur & 2,475 & 186.822 .058 & 21,889 & 19,414 \\
Cincin & 3,269 & 668.637 .464 & 78,341 & 75,072 \\
Karet & 0,367 & -917.435 .595 & $-107,491$ & $-107,858$ \\
Kertas & 2,000 & -882.582 .081 & $-103,407$ & $-105,407$ \\
Gas & 3,710 & -192.600 .171 & $-22,566$ & $-26,276$ \\
Tenaga & 122,678 & -22.958 .555 & $-2,690$ & $-125,368$ \\
kerja & & & & \\
\hline
\end{tabular}

1). Nilai efisiensi ekonomi penggunaan lahan sebesar 91,401 (NPMxi/Pxi > 1), artinya alokasi penggunaan lahan pada usahatani jamur tiram belum efisien secara ekonomi. Sehingga untuk mencapai tingkat alokasi penggunaan lahan yang optimal, pemakaiannya perlu dikurang sebesar 32,339 satuan.

2). Nilai efisiensi ekonomi penggunaan bibit sebesar 5,179 (NPMxi/Pxi > 1), artinya alokasi penggunaan bibit pada usahatani jamur tiram belum efisien secara ekonomi. Sehingga untuk mencapai tingkat alokasi penggunaan bibit yang optimal, pemakaiannya perlu dikurangi sebesar 18,005 satuan.

3). Nilai efisiensi ekonomi penggunaan serbuk gergaji sebesar $-169,805$ (NPMxi/Pxi < 1), artinya alokasi penggunaan serbuk gergaji pada 
usahatani jamur tiram tidak efisien secara ekonomi. Sehingga untuk mencapai tingkat alokasi penggunaan serbuk gergaji yang optimal, pemakaiannya perlu dikurangi sebesar 52,254 satuan.

4). Nilai efisiensi ekonomi penggunaan bekatul sebesar $\quad-212,834$ (NPMxi/Pxi < 1), artinya alokasi penggunaan bekatul pada usahatani jamur tiram tidak efisien secara ekonomi. Sehingga untuk mencapai tingkat alokasi penggunaan bekatul yang optimal, pemakaiannya perlu dikurangi sebesar 107,4503 satuan.

5). Nilai efisiensi ekonomi penggunaan polybag sebesar 5.024,241 (NPMxi/Pxi > 1), artinya alokasi penggunaan polybag pada usahatani jamur tiram belum efisien secara ekonomi. Sehingga untuk mencapai tingkat alokasi penggunaan polybag yang optimal, pemakaiannya perlu dikurangi sebesar 11.769,314 satuan.

6). Nilai efisiensi ekonomi penggunaan kapur sebesar 249,096 (NPMxi/Pxi > 1), artinya alokasi penggunaan kapur pada usahatani jamur tiram belum efisien secara ekonomi. Sehingga untuk mencapai tingkat alokasi penggunaan kapur yang optimal, pemakaiannya perlu ditingkatkan sebesar 19,414 satuan.

7). Nilai efisiensi ekonomi penggunaan cincin paralon sebesar 33,432 (NPMxi/Pxi > 1), artinya alokasi penggunaan cincin aralon pada usahatani jamur tiram belum efisien secara ekonomi. Sehingga untuk mencapai tingkat alokasi penggunaan cincin paralon yang optimal, pemakaiannya perlu ditambah sebesar 75,072 satuan.

8). Nilai efisiensi ekonomi penggunaan karet sebesar --45,872 (NPMxi/Pxi < 1), artinya alokasi penggunaan karet pada usahatani jamur tiram tidak efisien secara ekonomi. Sehingga untuk mencapai tingkat alokasi penggunaan karet/kertas yang optimal, pemakaiannya perlu dikurangi sebesar 107,858 satuan.

9). Nilai efisiensi ekonomi penggunaan kertas sebesar -25,217 (NPMxi/Pxi < 1), artinya alokasi penggunaan kertas pada usahatani jamur tiram tidak efisien secara ekonomi. Sehingga untuk mencapai tingkat alokasi penggunaan kertas yang optimal, pemakaiannya perlu dikurangi sebesar 105,407 satuan. Nilai efisiensi ekonomi penggunaan gas sebesar -8,755 (NPMxi/Pxi < 1), 
artinya alokasi penggunaan gas pada usahatani jamur tiram tidak efisien secara ekonomi. Sehingga untuk mencapai tingkat alokasi penggunaan gas yang optimal, pemakaiannya perlu dikurangi sebesar 26,276 satuan.

10). Nilai efisiensi ekonomi penggunaan tenaga kerja sebesar $-0,656$ (NPMxi/Pxi < 1), artinya alokasi penggunaan tenaga kerja pada usahatani jamur tiram tidak efisien secara ekonomi. Sehingga untuk mencapai tingkat alokasi penggunaan tenaga kerja yang optimal, pemakaiannya perlu dikurangi sebesar 125,3687 satuan.

\section{KESIMPULAN DAN SARAN}

\section{Kesimpulan}

Berdasarkan hasil penelitian yang dilakukan, maka dapat diambil kesimpulan sebagai berikut:

1) Hasil analisis dapat di baca bahwa, penjumlahan nilai koefisien sebesar 15,269 menunjukkan nilai elastisitas produksi $>1$. Nilai tersebut juga menunjukkan skala produksi petani jamur tiram berada pada tahap I atau increasingreturn to scale (IRS).

Daerah tersebut berarti secara ekonomis penggunaan faktor produksi belum berada pada tingkat optimum sehingga tidak rasional apabila produsen tidak menambah input pada daerah ini. karena koefisien bertanda positif.

2) Berdasarkan hasil penelitian diketahui bahwa penggunaan faktor produksi yang berpengaruh signifikan terhadap variasi produksi jamur tiram adalah lahan dan bekatul. Sementara bibit, serbuk gergaji. polybag, kapur, cincin paralon, karet, kertas,gas dan tenaga kerja tidak berpengaruh signifikan terhadap variasi produksi jamur tiram.

3) Tidak ada alokasi penggunaan sarana produksi pada usahatani jamur tiram pada UPT Pertanian Wilayah Sukaraja yang sudah mencapai tingkat efisisen secara ekonomi. Terdapat tujuh variabel yang mempunyai efisiensi ekonomi kurang dari satu dan bahkan ada yang bernilai negatif sehingga penggunaannya perlu dikurangi dan tiga variabel mempunyai nilai lebih dari satu dan bernilai positif sehingga penggunaannya perlu ditingkatkan.

\section{Saran}

1) Sehubungan dengan penggunaan factor produksi lahan, bibit, serbuk gergaji, bekatul dan tenaga kerja berpengaruh signifikan terhadap 
variasi hasil jamur tiram, maka penggunaannya agar diperhatikan baik kualitas maupun kuantitasnya.

2) Hasil penelitian menunjukan bahwa skala produksi dalam keadaan Increasing Return to Scale, sehingga masih mempunyai kemungkinan untuk meningkatkan skala usahatani. Oleh karena itu untuk meningkatkan hasil produksi para petani dapat memperluas areal luas lahannya dengan cara sewa atau bagi hasil, meningkatkan cara budidaya sesuai Good Agricultural Process (GAP) dan Good Harvested Process (GHP)

\section{DAFTAR PUSTAKA}

Badan Pusat Statisik. 2014. Tasikmalaya dalam Angka. Tasikmalaya : Badan Pusat Statistik.

Direktorat Jenderal Bina Produksi Hortikultura, Kementerian Pertanian. 2015. Perkembangan Ekspor Sayuran dan Biofarmaka Indonesia. Jakarta.

DinasPertanian Tanaman Pangan

KabupatenTasikmalaya. 2014. Laporan Perkembangan Tanaman Hortikultura di Kabupaten Tasikmalaya. Tasikmalaya: Dinas Pertanian Tanaman Pangan Kabupaten Tasikmalaya. 